\title{
Follicular growth and maturation in the domestic hen (Gallus domesticus)
}

\author{
R. J. Etches*§, H. E. MacGregor*†, T. F. Morrisł and J. B. Williams§
}

Department of Animal and Poultry Sciences, University of Guelph, Guelph, Ontario, Canada, NIG 2W1; $\ddagger$ Department of Agriculture and Horticulture, University of Reading, Whiteknights, Reading, RG6 2AJ, U.K.; and §Station de Recherches Avicoles, I.N.R.A., Centre de Tours, B.P. No. 1, 37380 Nouzilly, France

\begin{abstract}
Summary. The rate of follicular development in hens was assessed by measuring the increase in the diameter of follicles during $120 \mathrm{~h}$ before ovulation and the mass of follicles during $48 \mathrm{~h}$ before ovulation. The rate of follicular maturation was estimated by the ovulatory response of follicles to an injection of GnRH and the ability of follicles to produce progesterone in response to an injection of LH. Follicular diameter and follicular mass increased until ovulation, indicating that the follicle continues to sequester yolk material until ovulation occurs. The ovulatory response to $\mathrm{GnRH}$ and the production of progesterone in response to $\mathrm{LH}$ were negligible until $10 \mathrm{~h}$ after ovulation and then both aspects of follicular competence began to be functional. It was concluded that the size of the hen's ovum is not a primary factor regulating ovulability; rather, the acquisition of the ability to ovulate spontaneously is associated with the ability to produce progesterone in response to an LH stimulus. The ability to ovulate in response to $\mathrm{GnRH}$ was acquired more quickly in hens laying long sequences than in hens laying short sequences, indicating that the ovulatory response of the follicle can be used to assess the reproductive potential of laying hens.
\end{abstract}

\section{Introduction}

The ovary of the domestic hen contains a hierarchy of yolk-filled follicles. At approximately daily intervals, one of these follicles ruptures and the yolk-filled ovum is released. The timing of ovulation is very precise and this implies that an equally precise mechanism exists in the systems that regulate the recruitment of follicles into the hierarchy and/or their exit via ovulation.

Before a follicle can rupture and release the contained ovum, it must undergo some maturational process. The spectacular change in size which occurs during the 5-7 days before ovulation has led many investigators (Warren \& Conrad, 1939; Bacon \& Skala, 1968; Gilbert, 1971 ; Gilbert \& Wood-Gush, 1971 ; Imai, 1978) to equate this increase in size with the acquisition of the physiological machinery involved in the neuroendocrine interrelationships between the ovarian steroid hormones, gonadotrophin-releasing hormone (GnRH) and luteinizing hormone (LH) (see Follett \& Davies, 1979 for review).

In mammals, it is generally accepted that although size and follicular maturation are related, the precise control of follicular maturation is governed by steroidogenesis and the induction of specific

† Present address: Department of Animal and Poultry Science, University of Saskatchewan, Saskatoon, Saskatchewan, Canada $57 \mathrm{~N}$ 0W0. 
receptor proteins for the gonadotrophic hormones on the surface of the granulosa and theca cells (Richards, 1979). In the hen, studies of the binding capacity of the theca cells for folliclestimulating hormone (FSH) (Etches \& Cheng, 1981) and follicular steroidogenesis (Etches, Croze \& Duke, 1981; Hammond, Burke \& Hertelendy, 1981) during the last 4 days before ovulation, i.e. during the most rapid phase of follicular growth, have supported this generalized concept. It was the purpose of the present series of experiments to re-evaluate the relationship between follicular size and maturity and to develop alternative methods for assessing the physiological changes that precede spontaneous ovulation in the hen.

\section{Materials and Methods}

\section{Experiment 1}

Single-Comb White Leghorn (SCWL) hens were maintained and selected for study as described by Etches \& Cheng (1981). In brief, they were exposed to $14 \mathrm{~h}$ light and $10 \mathrm{~h}$ darkness (14L : 10D) and given access to food and water ad libitum. The times of oviposition were recorded automatically. Ovulation was considered to occur $30 \mathrm{~min}$ after oviposition of the previous ovum in the series (Warren \& Scott, 1935). At hourly intervals during the ovulatory cycle, $6-10$ hens were killed by cervical dislocation. The ovary was removed and the diameters of the first 4 or 5 follicles were measured to the nearest $1 \mathrm{~mm}$ across the stigma. The ovum was then removed from the largest 2 follicles by rupturing the follicular wall with a scalpel and allowing the contents to drain. The remaining thecal tissue was then weighed to the nearest $\mathrm{mg}$.

\section{Experiment 2}

SCWL hens which had completed a 12-month period of lay were used. The times of oviposition were recorded automatically to determine the position of the egg within the sequence and this production was verified by the position of the ovum in the oviduct at autopsy. GnRH ( $20 \mu \mathrm{g}$, Hoechst) was injected subcutaneously at $9,11,13$ or $15 \mathrm{~h}$ after a mid-sequence oviposition (which occurs $1 \mathrm{~h}$ before a mid-sequence ovulation), or at $9,11,13,15,17,21,25$ or $29 \mathrm{~h}$ after the penultimate oviposition of a sequence (which occurs $1 \mathrm{~h}$ before the terminal ovulation of a sequence). At each of these times between 5 and 17 hens were given GnRH. The hens were killed $8 \mathrm{~h}$ after the injection and the reproductive tract was observed during a post-mortem examination. The injection of GnRH was considered to have induced ovulation if an ovum was present in the body cavity, infundibulum or magnum since ovulation follows an injection of LHRH by approximately $7 \mathrm{~h}$ and the ovum enters the magnum within $0.5-1 \mathrm{~h}$ after ovulation.

Ovulations which followed injections of GnRH were considered to reflect a change in the sensitivity of the follicles to circulating concentrations of LH since previous studies have shown that, except for a brief period during and after the preovulatory surge of LH, pituitary sensitivity to GnRH does not vary appreciably (Wilson \& Sharp, 1975; Etches \& Cunningham, 1976).

\section{Experiment 3}

SCWL hens were maintained as described above and injected intravenously into the wing vein with 10,20 or $50 \mu \mathrm{g} \mathrm{LH} \mathrm{(NIH-LH-SI16)} \mathrm{per} \mathrm{kg} \mathrm{body} \mathrm{weight} \mathrm{in} 0.5 \mathrm{ml}$ saline $(9 \mathrm{~g} \mathrm{NaCl} / \mathrm{l})$. The injections were given $4 \cdot 5-9.0 \mathrm{~h}$ after a mid-sequence ovulation or $26-30 \mathrm{~h}$ after the terminal ovulation of a sequence. The ability of each dose to provoke an increase in the plasma concentration of progesterone was tested in 5 hens at each stage of the ovulatory cycle. Control hens were injected with saline. Blood samples were taken immediately before and at 10,30,60 and $90 \mathrm{~min}$ after injection. The concentration of progesterone in plasma was measured using the solid-phase radioimmunoassay described by Williams \& Sharp (1978a). The minimum detectable level of 
progesterone was between 0.14 and $0.10 \mathrm{ng} / \mathrm{ml}$ and the inter- and intra-assay coefficients of variation were $3 \cdot 2$ and $13 \cdot 1 \%$, respectively.

\section{Experiment 4}

This experiment used 2 flocks of SCWL hens. The first flock had completed a 12-month period of lay and the second flock was used during the 2 nd month of lay. The hens were selected for study if they laid sequences containing $2-4$ eggs (i.e. short sequences) or $>10$ eggs (i.e. long sequences). All of the hens were injected subcutaneously adjacent to the femoral vein with $25 \mu \mathrm{g} \mathrm{GnRH} 12,13$ or 14 $\mathrm{h}$ after a mid-sequence ovulation. The hens were killed $8 \mathrm{~h}$ after the injection, the reproductive tract was exposed and the occurrence of ovulation was determined as described for Exp. 3

\section{Results}

\section{Experiment 1: changes in follicular diameter and follicular mass before ovulation}

The changes in follicular diameter during the last 5 days of development were examined by fitting a regression equation to the diameters of the $F_{1}, F_{2}, F_{3}, F_{4}$ and $F_{5}$ follicles. The mean follicular diameter of each hourly interval during the $120 \mathrm{~h}$ before ovulation is illustrated in Textfig. 1. This equation accounted for $98 \%$ of the variation in follicular diameter and the simple correlation between the mean follicular diameter and time was 0.99 .

The changes in follicular weight at each hourly interval during the last $48 \mathrm{~h}$ before ovulation were also analysed by regression and correlation. Only $75 \%$ of the variation in follicular weight could be explained using a linear regression equation and the use of polynomial or exponential functions did not improve this fit. Follicular weight may appear to be a less precise estimate of follicular maturity than follicular diameter only because the range of the dependent variable was smaller; but it may also have been related to a variable contribution of the epithelium, connective tissue coat and/or the follicular stalk to follicular weight. The simple correlation between the mean follicular weight and time was $\mathbf{0 \cdot 8 6}$. These data are represented in Text-fig. 2.

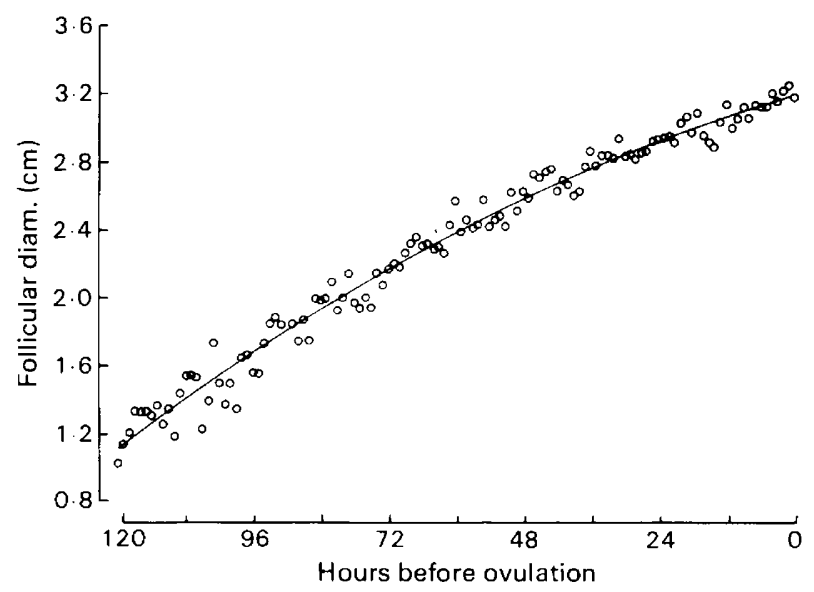

Text-fig. 1. Changes in the diameter of the 5 largest follicles in the hierarchy of the hen during $120 \mathrm{~h}$ preceding ovulation. These data are described by the quadratic equation: diameter = $2.47 \times 10^{-2}($ time $)-6.36 \times 10^{-5}\left(\right.$ time $\left.^{2}\right)+1 \cdot 11$. 


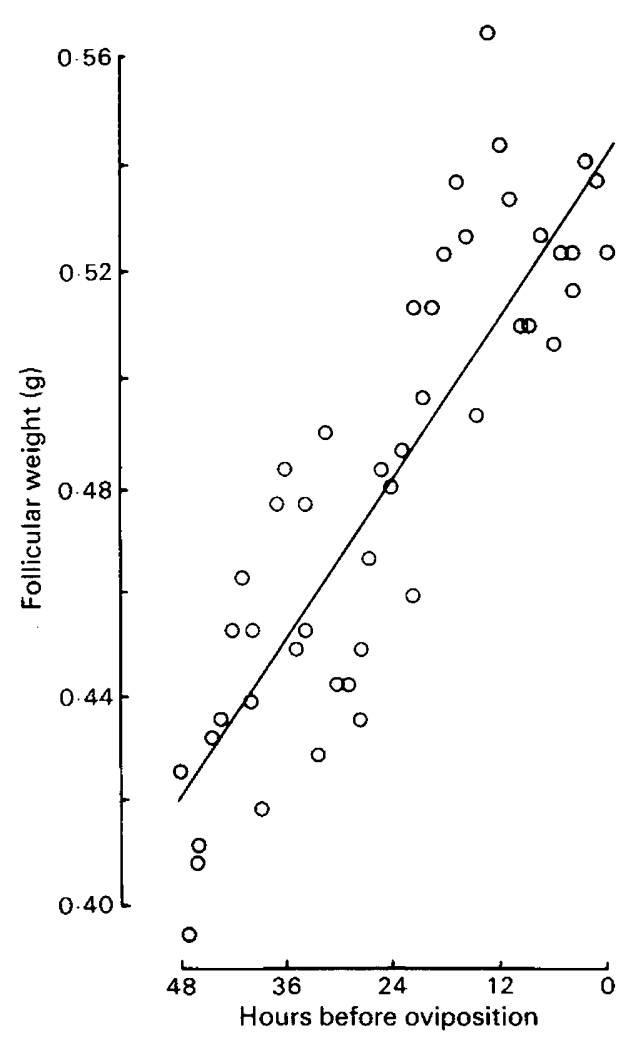

Text-fig. 2. Changes in the mean weight of the 2 largest follicles of the hen during $48 \mathrm{~h}$ preceding ovulation. These data are described by the equation: weight $=2.6 \times 10^{3}$ (time) + 0.42 .

Experiment 2: induction of ovulation in response to GnRH given at various times during the ovulation cycle

As shown in Text-fig. 3, the largest follicle in the hierarchy did not ovulate in response to the injection during the first $8 \mathrm{~h}$ after a mid-sequence or a terminal ovulation. Between 10 and $16 \mathrm{~h}$ after ovulation, the largest follicle in the hierarchy acquired responsiveness to the injections. Although fewer than $25 \%$ of the hens injected $10 \mathrm{~h}$ after ovulation responded to the GnRH, this response increased to approximately $80 \%$ after $16 \mathrm{~h}$ had elapsed.

The response of the follicle to GnRH was related to the interval from the preceding ovulation and not to the time of the impending ovulation. The first follicle of the sequence began to acquire sensitivity to GnRH about $25 \mathrm{~h}$ before its impending ovulation, whereas sensitivity to $\mathrm{GnRH}$ by a follicle destined to become a mid-sequence ovulation first became evident about $10 \mathrm{~h}$ before its impending rupture (Text-fig. 3).

Experiment 3: progesterone secretion by follicles stimulated with $L H$ at various stages during the ovulation cycle

There was no change in the concentration of progesterone after an injection of saline. The administration of $\mathrm{LH}$ caused a significant increase in the plasma concentration of progesterone at both stages of the ovulation cycle and this increase was greater when LH was given $26-30 \mathrm{~h}$ after ovulation than at $4.5-9.0 \mathrm{~h}$ after ovulation (Text-fig. 4). When $\mathrm{LH}$ was administered $4 \cdot 5-9.0 \mathrm{~h}$ after 

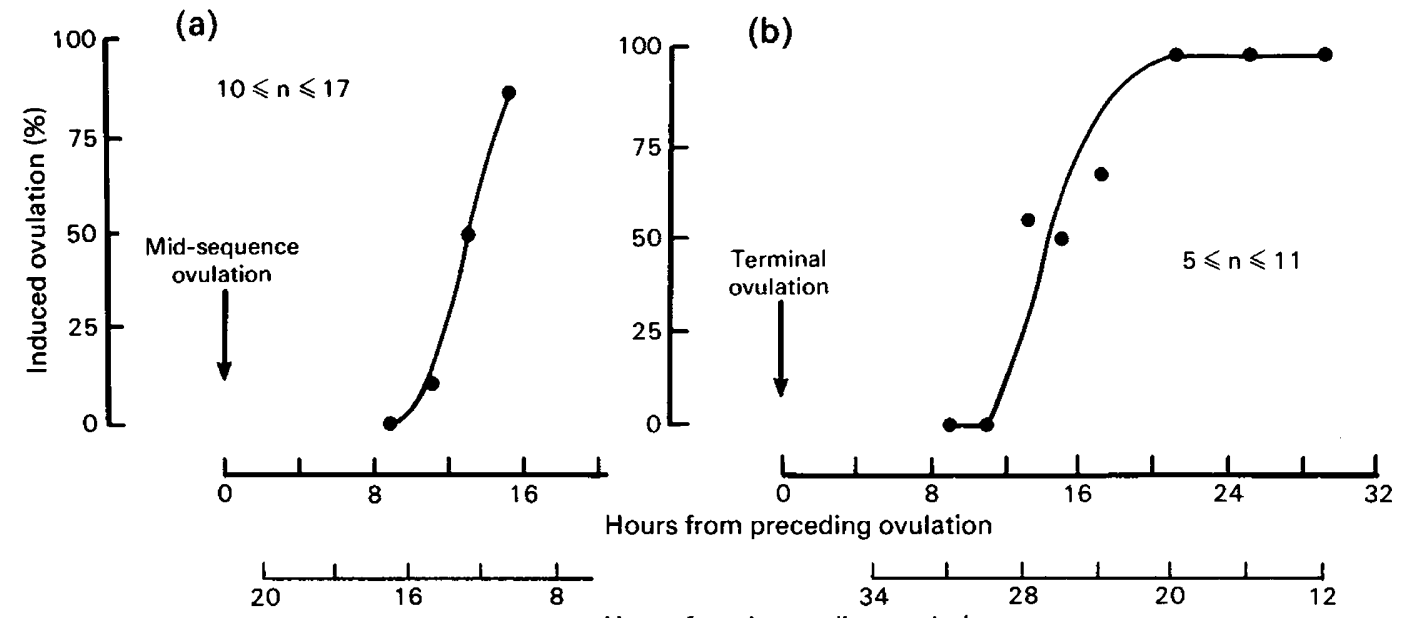

Hours from preceding ovulation

Hours from impending ovulation

Text-fig. 3. The percentage of ovulations induced by an injection of GnRH given (a) 8-16 h after a mid-sequence ovulation or (b) 8-28 $\mathrm{h}$ after the terminal ovulation of a sequence. The number of hens injected is indicated by $n$.

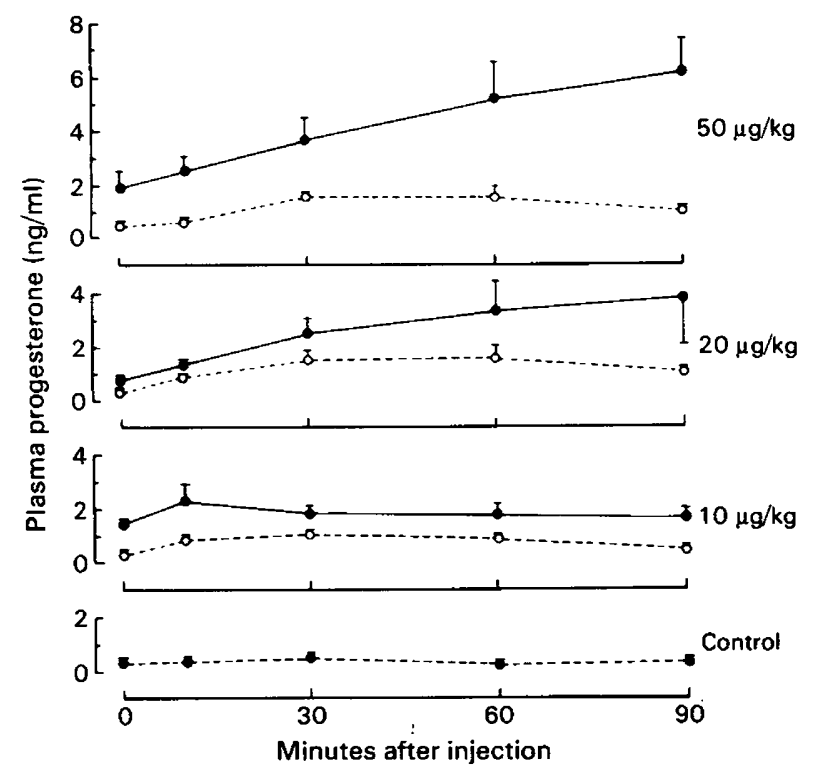

Text-fig. 4. The concentration of progesterone (mean \pm s.e.m.) in the plasma of hens given ovine LH 26-30 h after the final ovulation of a sequence $(--0), 4 \cdot 5-9.0 \mathrm{~h}$ after a midsequence ovulation $\left(\mathrm{O}_{---} \mathrm{O}\right)$ or after an injection of saline (O---).

ovulation, peak values were observed $30-60 \mathrm{~min}$ after the injection. After injection of the two largest doses of $\mathrm{LH} 26-30 \mathrm{~h}$ after ovulation, the secretion of progesterone increased for at least 90 min.

Experiment 4: the induction of ovulation in response to GnRH in hens laying short and long sequences

The results are given in Table 1. Ovulations were never induced until $14 \mathrm{~h}$ elapsed after the previous ovulation in the hens laying short sequences. However, in the hens laying long sequences, 
Table 1. The ovulatory response of hens laying long and short sequences to an injection of $25 \mu \mathrm{g} \mathrm{GnRH}$ given 12,13 or $14 \mathrm{~h}$ after a mid-sequence ovulation

\begin{tabular}{|c|c|c|c|}
\hline $\begin{array}{l}\text { Sequence } \\
\text { length }\end{array}$ & $\begin{array}{c}\text { Mean }( \pm \text { s.d.) } \\
\text { interval (h) } \\
\text { between oviposition } \\
\text { times (h) }\end{array}$ & $\begin{array}{l}\text { Time of } \\
\text { GnRH after } \\
\text { previous } \\
\text { ovulation }(\mathrm{h})\end{array}$ & $\begin{array}{l}\text { No. of hens } \\
\text { ovulating }\end{array}$ \\
\hline Long & $24.22 \pm 0.20$ & $\begin{array}{l}14 \\
13 \\
12\end{array}$ & $\begin{array}{c}11 / 15 \\
4 / 16 \\
0 / 6\end{array}$ \\
\hline Short & $26.01 \pm 0.29$ & $\begin{array}{l}14 \\
13\end{array}$ & $\begin{array}{l}2 / 10 \\
0 / 10\end{array}$ \\
\hline
\end{tabular}

a $25 \%$ response was observed $13 \mathrm{~h}$ after the preceding ovulation and $73 \%$ of the hens of this group ovulated when injected $14 \mathrm{~h}$ after the preceding ovulation.

\section{Discussion}

Many previous studies of the growth of the hen's ovum have been conducted by sequentially feeding fat soluble dyes (Warren \& Conrad, 1939; Bacon \& Skala, 1968; Gilbert \& Wood-Gush, 1971; Williams \& Sharp, 1978b) or Evans Blue (Gilbert, 1970). The pattern of uptake of the components of the yolk complex has been interpreted as an indication that follicular growth ceases before ovulation occurs (Bacon \& Skala, 1968; Bacon \& Cherms, 1968) and that failure of hens to ovulate on the day between sequences is related to the ability of the follicles to sequester a sufficient mass of yolk material (Gilbert \& Wood-Gush, 1971; Imai, 1978). However, the increase in follicular weight (Text-figs $1 \& 2$ ) would suggest that, while some components may stop entering the follicle at various times before ovulation, overall growth continues until within $1 \mathrm{~h}$ of ovulation.

Evidence from several studies supports the idea that follicular size is not necessarily related to the ability of a follicle to ovulate. Using appropriately timed injections of ovulation-inducing hormones, Neher \& Fraps (1950) were able to add several additional eggs to sequences although each successive yolk was smaller than its predecessor. The data presented in Text-figs 1 and 2 indicate that the ovum and the follicle continue to grow up to the time when LH release triggers ovulation. Since the diameter of the ovum and the weight of the follicle are more direct indices of the increase in the mass of the follicle and the ovum than the uptake of a dye by one component of a very complex mixture of substances in the yolk, it seems likely that the 'resting phase' before ovulation which was proposed by Bacon \& Skala (1968) does not normally occur in the hen. It has been known for some time that the first ovulation of a sequence usually releases the largest yolk (Atwood \& Weakly, 1917; Bastian \& Zarrow, 1955) and despite statements to the contrary (Imai, 1978) the same relationship has been found in a modern, commercial breed of SCWL hens (R. J. Etches, unpublished data). It therefore seems reasonable to conclude that the follicle continues to accumulate at least some of the yolk precursors during the period between sequences and that the inability to sequester yolk precursors probably does not terminate the sequence. From a theoretical viewpoint, the proposal that the sequence length might be dictated by gaps in the follicular hierarchy fails to provide an explanation for the decreasing lag (i.e. difference between successive oviposition times) at the beginning of sequences, the minimal lag in the middle of sequences and the increasing lag at the end of sequences. Yolk weight at ovulation is not constant in any one bird but changes with age. For example, yolk weight increased by $168 \%$ during the first 3 months of lay (initial mean yolk weight $10.2 \mathrm{~g}$ (range 8.9-11.8 g) and after 3 months of lay $17.1 \mathrm{~g}$ (range 13.2$19.5 \mathrm{~g}$ )) although the rate of ovulation did not change (J. B. Williams unpublished observations).

Another suggested mechanism by which movements of follicles through the hierarchy are 
regulated was proposed by Fraps $(1955,1970)$. He showed that the sensitivity of the follicle to respond to exogenous LH by ovulating was a function of the time which had elapsed since the previous ovulation. In the present study, an identical relationship between the time from the preceding ovulation and the acquisition of ability to ovulate was shown by the results of Exp. 2 using GnRH (Text-fig. 3). The follicle becomes sensitive to the LH produced in response to GnRH (Text-fig. 3) or injected from exogenous sources (Fraps, 1970) approximately $13 \mathrm{~h}$ after the previous ovulation. The number of hours during which the ovum is destined to wait within the ovary before being ovulated is unrelated to the acquisition of follicular sensitivity to LH since a mid-sequence ovum is retained within the competent follicle for only $11-12 \mathrm{~h}$ whereas the first ovum is retained within the follicle for $22-26 \mathrm{~h}$ after the acquisition of sensitivity to $\mathrm{LH}$.

Since progesterone and $\mathrm{LH}$ are interrelated in a positive feedback system in hens (Etches \& Cunningham, 1976; Wilson \& Sharp, 1976) we attempted to relate some aspect of steroidogenesis to the changing sensitivity to LH. The data in Text-fig. 4 clearly demonstrate that the follicle gains the ability to produce progesterone in response to an LH stimulus after more than $4.5-9.0 \mathrm{~h}$ have elapsed from the previous ovulation. These data are very similar to those reported by Etches \& Cunningham (1976) who stimulated progesterone secretion indirectly by GnRH treatment. Both of these studies indicate that the progressive acquisition of the ability of the follicle to produce progesterone in response to $\mathbf{L H}$ is physiological change which causes the largest follicle in the hierarchy to become ovulable. This conclusion is also consistent with the observation that all of the preovulatory progesterone in the hen is produced by the largest follicle which is destined to ovulate within $5 \mathrm{~h}$ (Etches et al., 1981) and the more general premise of Rondell (1974) that progesterone synthesis is a final phase in the maturation of ovarian follicles in vertebrates.

Historically, follicles which are capable of ovulating have been described as developed, mature, ripe or competent. In this attempt to quantitate more precisely the events occurring during the final $20-40 \mathrm{~h}$ before ovulation, a standardized nomenclature was adopted. Thus, 'follicular growth' was defined as the change in the mass of the follicle and its contents and 'follicular competence' was used to describe the state attained by growing follicles which enabled them to be prematurely ovulated or activated by an exogenous stimulus such as LH or GnRH. Whether or not the acquisition of competence indicated that the follicle had completed the maturational process remains, however, a moot question. For example, the first follicle of a sequence was competent, i.e. it could be ovulated prematurely (Text-fig. 3) and would produce progesterone in response to an exogenous stimulus (Text-fig. 4) several hours before it ovulated spontaneously. It is not certain, however, whether further maturational changes occurred within the follicle after competence was acquired or whether the timing of spontaneous ovulation of the competent and/or mature follicle was determined by a physiological event which was independent of follicular maturation. Thus, the use of the term 'follicular maturity' was avoided due to our inadequate knowledge of the systems which permit spontaneous ovulation.

Differences in the rate of egg production may be caused by differences in the rate at which follicles become mature within the hierarchy. Furthermore, it should be possible to quantitate this difference by measuring the rate at which follicles acquire competence. The data in Table 2 are consistent with this hypothesis since hens laying long sequences ovulate in response to an injection of GnRH more quickly than hens laying short sequences. However, measuring competence by the ovulatory response to $\mathrm{GnRH}$ is a cumbersome and expensive procedure and its utility is limited because the hens must be killed. Future research must therefore be directed toward finding more accurate and convenient characters that reflect the rate of maturation of the follicle and, hence, the reproductive potential of the individual laying hen.

This work was supported in part by the Ontario Ministry of Agriculture and Food and the Natural Sciences and Engineering Research Council of Canada, Grant No. A 0062. We also thank the NIAMMD, NIH, for the ovine LH. 


\section{References}

Atwood, H. \& Weakly, C.E. (1917) Certain characteristics of hen's eggs. Bull.W. Va Agric. Exp. Stn 166, 1-35.

Bacon, W.L. \& Cherms, F.L. (1968) Ovarian follicular growth and maturation in the domestic turkey. Poultry Sci. 47, 1303-1314.

Bacon, W.L. \& Skala, J.H. (1968) Ovarian follicular growth and maturation in laying hens and the relation to egg quality. Poultry Sci. 47, 1437-1442.

Bastian, J.W. \& Zarrow, M.X. (1955) A new hypothesis for the asynchronous ovulatory cycle of the domestic hen (Gallus domesticus). Poultry Sci. 34, 776-777.

Etches, R.J. \& Cheng, K.W. (1981) Changes in the plasma concentrations of luteinizing hormone, progesterone, oestradiol and testosterone and in the binding of follicle stimulating hormone to the theca of follicles during the ovulation cycle of the hen (Gallus domesticus). J. Endocr. 91, 11-22.

Etches, R.J. \& Cunningham, F.J. (1976) The interrelationship between progesterone and luteinizing hormone during the ovulation cycle of the chicken. $J$. Endocr. 71, 51-58.

Etches, R.J., Croze, F. \& Duke, C.E. (1981) Plasma concentrations of luteinizing hormone, progesterone, testosterone and estradiol in follicular and peripheral plasma during the ovulation cycle of the hen. $A d v$. Physiol. Sci. 33, 89-98.

Follett, B.K. \& Davies, D.T. (1979) The endocrine control of ovulation in birds. In Animal Reproduction, pp. 323-344. Ed. H. H. Hawk. Wiley, New York.

Fraps, R.M. (1955) Egg production and fertility in poultry. In Progress in the Physiology of Farm Animals, Vol. II. pp. 671-740. Ed. J. Hammond. Butterworth, London.

Fraps, R.M. (1970) Photoregulation in the ovulation cycle of the domestic fowl. In La Photorégulation de la Reproduction chez les Oiseaux et les Mammiferes, pp. 281-306. Eds J. Benoit \& Assenmacher. CNRS (No. 172), Paris.

Gilbert, A.B. (1970) Yolk deposition in the chicken oocyte and its relationship with ovulation. J. Reprod. Fert. 23, 539-540.

Gilbert, A.B. (1971) The ovary. In Physiology and Biochemistry of the Domestic Fowl, Chap. 50, pp. 11631202. Eds D. J. Bell \& B. M. Freeman. Academic Press, London.
Gilbert, A.B. \& Wood-Gush, D.G.M. (1971) Ovulatory and ovipository cycles. In Physiology and Biochemistry of the Domestic Fowl, Chap. 57, pp. 13531374. Eds D. J. Bell \& B. M. Freeman. Academic Press, London.

Hammond, R.W., Burke, W.H. \& Hertelendy, F. (1981) Influence of follicular maturation on progesterone release in chicken granulosa cells in response to turkey and ovine gonadotropins. Biol. Reprod. 24, 1048-1055.

Imai, K. (1978) Rapid growth of the ovarian follicle in laying hens, with special reference to the clutch. Proc. 16th Wld Poult. Sci. Congr., Rio de Janeiro 13, 32-37.

Neher, B.H. \& Fraps, R.M. (1950) The addition of eggs to the hen's clutch by repeated injection of ovulationinducing hormones. Endocrinology 46, 482-488.

Richards, J.S. (1979) Hormonal control of ovarian follicular development: a 1978 perspective. Recent Prog. Horm. Res. 35, 343-373.

Rondell, P. (1974) Role of steroid synthesis in the process of ovulation. Biol. Reprod. 10, 199-215.

Warren, D.C. \& Conrad, R.M. (1939) Growth of the hen's ovum. J. agric. Res. 58, 875-893.

Warren, D.C. \& Scott, H.M. (1935) The time factor in egg formation. Poult. Sci. 14, 195-207.

Williams, J.B. \& Sharp, P.J. (1978a) Age dependent changes in the hypothalomo-pituitary-ovarian axis of the laying hen. J. Reprod. Fert. 53, 141-146.

Williams, J.B. \& Sharp, P.J. (1978b) Ovarian morphology and rates of ovarian follicular development in laying broiler breeders and commercial egg producing hens. Br. Poultry Sci. 19, 387-395.

Wilson, S.C. \& Sharp, P.J. (1975) Changes in the plasma concentration of luteinizing hormone after an injection of progesterone at various times during the ovulatory cycle of the domestic hen (Gallus domesticus). J. Endocr. 67, 59-70.

Wilson, S.C. \& Sharp, P.J. (1976) Induction of luteinizing hormone release by gonadal steroids in the ovariectomized domestic hen. J. Endocr. 71, 87-98.

Received 16 July 1982 